\title{
A family of viruses Geminiviridae and analysis of phytosanitary risk in Ukraine
}

\author{
A. Kyrychenko, \\ Candidate of Biological Sciences \\ Institute of Microbiology and Virology. DK Zabolotny National Academy of Sciences of Ukraine
}

The purpose. To study of the basic biological properties of viruses of family Geminiviridae - the important virus pathogens of food and ornamental crops in the majority of the countries of the world. Analysis of correlation between risk of the contagions caused by viruses of this family, change of climatic conditions and ecology of a transmitting agent. Methods. Monographic, economic-statistical, theoretical generalization. Results. Biological features of viruses of family Geminiviridae and their transmitting agents are presented. Analysis of epidemiological situation concerning viruses Geminiviridae in Ukraine in view of probability and possible after-effects of introduction of viruses and their transmitting agents in agro-ecosystems is made. Conclusions. To one of means of prevention virus epiphytoties should become analysis of phytosanitory risk with the purpose of scientific and engineering justification of phytosanitory provisions which are applied concerning hazardous organisms or the imported goods.

Key words: viruses of plants, Geminiviridae, tobacco whitefly Bemisia tabaci, climate, phytosanitory supervisory control.

The viruses of Geminiviridae family cause many economically important virus diseases of crops worldwide, limiting the vegetable production in tropical, subtropical and temperate regions. The Geminiviridae as a major plant pathogen in this countries [13] infects a wide range of cultures, making a serious threat to farming industry. The devastating effects of Maize streak virus (MSV) in Africa, Tomato yellow leaf curl virus in the United States, Tomato pseudo-curly top virus (TPCTV) in the south-eastern United States, Bean golden yellow mosaic virus (BGYMV) in Central America and Beet curly top virus (BCTV) worldwide show the relevance of the studding these pathogens in Ukraine to develop preventive strategies aimed at early detection and identification to create resistant plant varieties and to control their vectors.

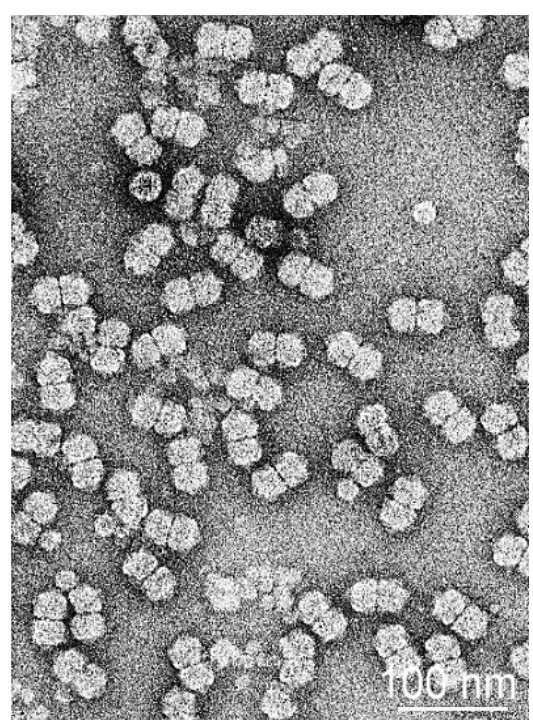

Fig. 1 Electron micrograph of Geminiviridae prepared by Dr R.G. Milne [12]

The first description of a geminivirus disease have been recorded as early as 752 AD in the Man'yoshu, classical Japanese poetry. Recently it have been shown the autumnal appearance of eupatorium plants in 
the summer, are caused by a geminivirus/satellite disease complex [24]. Over the last two decades the viruses massively appear outside of theirs ecological niches - in tropical and subtropical regions [17]. Such rapid expansion of the diseases caused by these viruses scientists associated with the emergence of new virus strains and increasing the number of virus vectors as a result of global warming and emerging insecticide resistance [25]. In addition, importation of infected planting material, the introduction of new crops or susceptibility genes through tissue culture and also climatic factors contribute to the spread of these viruses.

The most begomoviruses are transmitted by the whitefly species, Bemisia tabaci (Hemiptera, family Aleyrodidae), leafhopper (Cicadellidae) or treehopper (Membracidae) [14] and are pathogens of cereals, vegetables and bast crops, posing a serious threat to agriculture worldwide. In particular, this viruses infect most important crops: Solanaceae: tomatoes, tobacco, pepper, petunia; Fabaceae: Common Bean, Lima beans, soybeans; Malvaceae: cotton, okra; Euphorbiaceae: cassava; Cucurbitaceae: melon, watermelon, zucchini. Viruses of this family are not transmitted with seeds [5], some of them can be transmitted by mechanical inoculation of infected plant sap [23].

Interestingly, geminiviruses are one of the few plant virus families using a DNA genome. According to Rojas et al., most plant viruses use an RNA genome, which suggests that plants have controlled the evolution of DNA viruses [22]. The Geminiviridae evolution went towards improving the mechanisms that would allow to control the plant cell life cycle, move freely from cell to cell and throughout the plant, avoiding factors of antiviral defense system of the host plant. Thanks to these features geminiviruses became one of the most harmful pathogens of wide range crops, leading to huge losses in the agricultural sector in different countries.

In 1978, the International Committee on Taxonomy of viruses (ICTV) based on the unique morphology of virions (extremely small size, dual particle) and genomic material in the form of a circular single-stranded DNA (Matthews, 1979) recognized Geminiviridae as a separate family. At that time (1978) only four viruses (BGMV, CLV, CSMV, MSV) were described, in $1981-13$. Currently Geminiviridae is one of the largest and most important families of plant viruses - 359 complete genomes of viruses there are the NCBI database. In the present-day ICTV recognizes four genera (Mastrevirus (29 Species), Begomovirus (288 Species), Curtovirus (3 Species) and Topocuvirus (1 Species) in the family Geminiviridae, according to the type of vectors, genome organization, genome-wide pairwise sequence identities and host plant range [2]. In 2014 it was announced the establishment of three new genera (Becurtovirus, Eragrovirus and Turncurtovirus that were highly divergent from previously known and, in some cases, had unique genome architectures [27].

The genus Begomovirus is comprised of 196 member species, representing the largest genus of family Geminiviridae. Viruses of the genus Begomovirus are transmitted by the ubiquitous whitefly Bemisia tabaci and are the most numerous and economically most destructive viruses among the geminiviruses [26].

Begomoviruses typically have genomes consisting of two separately encapsidated genomic components, known as DNA-A and DNA-B. At the end of 1980 it were found begomoviruses with monopartite (one ssDNA component) genome. These viruses have true monopartite genomes containing only a DNA-A-like molecule that is sufficient to cause wild-type disease symptoms and encodes all functions necessary for replication and moving of the virus through the plant [19]. Some geminiviruses are associated with single-stranded DNA satellites, referred to as alphasatellites and betasatellites, the latter playing an essential role in maintenance of the disease. All functions of betasatellites described so far, are mediated by the $\beta C 1$ protein. The protein has multiple functions: pathogenicity determinant (determines the symptoms of the infection), suppressor of posttranscriptional gene silencing (PTGS) to overcome host plant defence, potential involvement in virus movement, upregulation of viral DNA levels in planta. There no specific function are known attributed to alphasatellites. Alphasatellites cause a decrease in viral DNA levels in the plant, leading to the suggestion that when alphasatellites reduce virus titer, infected plants become less affected and may host begomovirus and onward transmission for a longer time period [4].

Small, single-stranded DNA genomes of geminiviruses encode little number (5-7) proteins and uses the host's DNA replication proteins to amplify its genome and create a productive infection, maintaining a high 
level of viral DNA replication and distribution. Since geminiviruses encode for a few proteins, so it only supplies the DNA for viral replication and manipulates the metabolism of infected cells to control the host plant's cell cycle, allowing cells in which the virus has used up its DNA replicating capabilities to regain the ability to support high levels of (viral) DNA replication. The proteins encoded by the begomoviruses are divided into four groups: Rep and REn proteins are involved in DNA replication; TrAP proteins and/or AC4 take part in host plant gene regulation and inhibit the silencing suppression activity; coat protein (CP) required for encapsidation, insect transmission and movement in plants; MP, NSP - are responsible for transport of viral DNA. The first three groups are encoded by DNA-A component and the coding sequences for movement proteins - by DNA B [7].

Based on the genome organization, the genetic diversity and the geographical distribution, begomoviruses have been divided into two groups: Old World (OW, Europe, Africa, Asia and Australia) and New World (NW, America) begomoviruses [21]. According to the modern concepts of crop diversification, there are at least eight major centers of plant origin [10]. There is an enormous diversity of particular plant families in the centers of origin, and less diversity on the periphery. Geminivirus centers of diversification can be identified from the phylogenetic tree built from all sequences available and can be described as the areas where a maximum number of geminivirus species have been identified so far, and a similar evaluation can be done for their satellites. It was identified eight different geographical locations as centers of diversification for "geminiviruses" (Fig. 2). These centers are: A- Australia, B- Japan, C- South China, D- Indian subcontinent, E- Sub-saharan Africa, F- Mediterranean-European region, G- South America and H- Central America. Together, the Chinese and Indian host centers more than $46 \%$ of geminivirus species, $94 \%$ of betasatellite species and $98 \%$ of alphasatellite species. The presence of this enormous diversity for geminiviruses and associated satellites points towards designating Indo-China as a center of origin for these viral and subviral entities.

Humans have played an important role in the last century to promote the emergence of many geminivirus diseases, thereby impacting their evolution. The greatest molecular diversity of geminiviruses and their satellites resides in Southeast Asia revealing a possible center of origin.

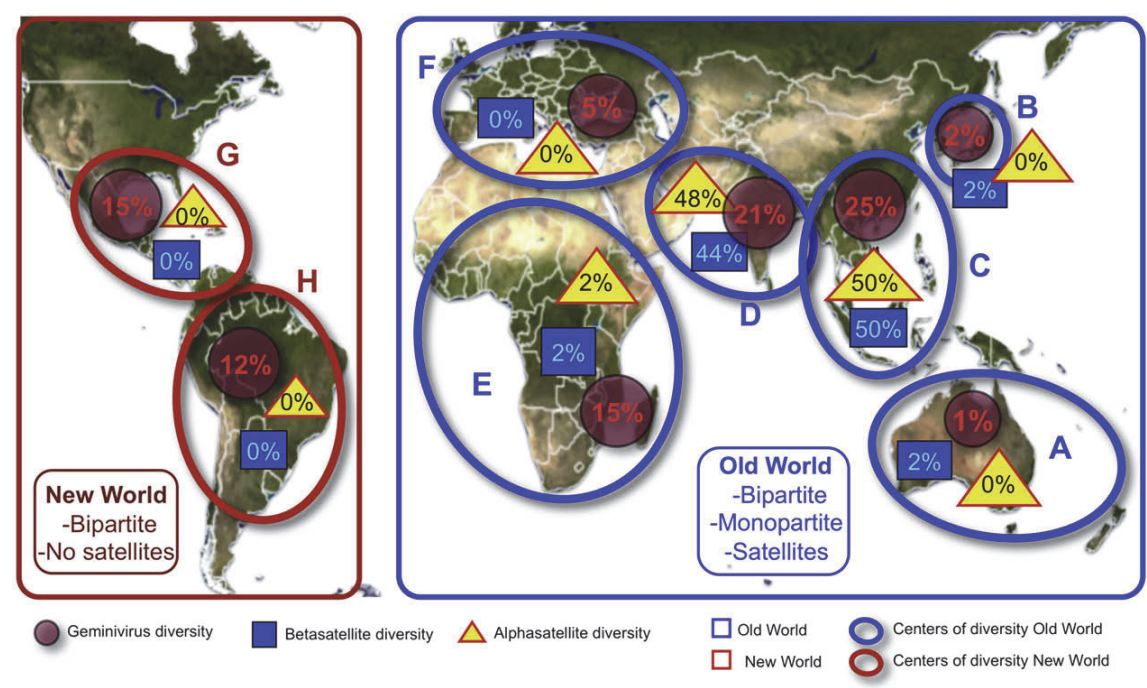

Fig. 2. Geographical distribution of geminiviruses Nawaz-ul-Rehman M.S., Fauquet C.M. [20]

Eight different centers of diversification $(\mathrm{A}-\mathrm{H})$. The percentages in circles represent the percentage of geminivirus species, in boxes - betasatellite species, in triangles - the percentage of alphasatellite species. A - Australia, B - Japan, C - China, D - Indian subcontinent, E - Africa, F - Mediterranean-European region, $\mathrm{G}$ - Central America, $\mathrm{H}$ - South America

Surprisingly, the diversity centers for geminiviruses do not match perfectly with those of host crops. There is an overlap between the crop and virus centers for five of eight geminivirus centers, with only the 
Australian, African and South American centers differing. All of this data strongly support the theory that local viruses invaded endemic or introduced crops, suggesting rapid host changes [20].

Geminiviruses have been emerging as a worldwide problem since the 1960s, and frequently, epidemics can be linked to human activities. Insect vectors responsible for the spread of geminiviruses play an important role in geminivirus evolution. Persistent and circulative mode of virus spread within adult insects and physical interaction between insects and geminiviruses show the co-evolutionary adaptation between geminiviruses and their insect vectors. Moreover, the evolution Geminivirus through their natural vectors associated with changes in the area of CP gene, which is responsible for the formation of a capsid and the virus spread by insects [3]

The emergence of diseases transmitted by whiteflies facilitate genetic changes viral genome mutation and recombination, changes in the population vectors combined with polyphagia of the main vector - Bemisia tabaci, and the spread of plant material or insect vectors in the trading process vegetables and ornamental plants. Since the role of humans in the spread of viral diseases is obvious [18], recently much attention is taken away the impact of climate change on the epidemiological status of the integrated system Geminiviridae/Bemisia tabaci [16]. Thus, $55 \%$ of the areas affected by Geminiviridae are in the wet/dry conditions, $22 \%$ - in tropical and subtropical dry/wet, and the rest viruses - in wet equatorial and coastal regions. The climate in Ukraine largely changes in line with the global pace. At this point, Ukraine is not among the countries most vulnerable to the global dynamics of climate change, reports the UN international group of experts. However, a permanent rise in the average annual temperature may result in dramatic transformations in a vast part of Ukraine's physical and climatic landscape. The country's climate is going to be less continental, shift of the climate zones is the slowly moving north and alters natural ecosystems climate. Under these conditions, the main problems are the mass reproduction of pests, erosion and desertification of fertile soil, arid climate [11]. Due to climate change in Ukraine arthropods will change their life rhythms and cycles, insects will adapt to the new, hotter climate. In addition, the risk of non-core areas for certain species of insects will increase. In 2014, as experts predicted, the size of areas contaminated with tobacco whitefly, remained unchanged, but the weather changes (warming trend) are favorable for the pest development [28]. The tobacco whitefly will be not only a great threat to the greenhouses, but also for open ground plants, as the climate of our region may be suitable for its existence.

\section{Conclusions}

Thus, to successfully control the epidemiological situation with Geminiviridae in Ukraine, it is required the comprehensive use of various control measures. First of all, it is required broad knowledge about ecology and epidemiology of these viruses and their vectors. This will allow time to establish of quarantine regime and develop measures for successful localization and elimination of the pests. Since, for most alien species of pests a greenhouse is the perfect place to adapt to new conditions, a thorough examination of greenhouses is necessary, especially those ones that use imported seed or planting material. Ukrainian enterprises and organizations engaged in importation, exportation, cultivation and sale of greenhouse crops should be checked and controlled as well. It is urgent to develop integrated management concepts on viral diseases that will combine the plant resistance, cultivation conditions, chemical and biological controls. Decisions on protective actions depend on correctly assessing of probability and possible consequences of the introduction of plant viruses and their vectors, followed by the spread in agrocenoses.

\section{Bibliography}

1. Chelombitko A. Suchasnyy stan poshyrennya karantynnykh orhanizmiv v Ukrayini/A. Chelombitko, O. Bashyns'ka//Propozytsiya. - 2014. — № 4. - S. 84 - 90.

2. Begomovirus disease complex: emerging threat to vegetable production systems of West and Central Africa /W.N. Leke, D.B. Mignouna, J.K. Brown et al.//Agriculture \& Food Security. — 2015. — V. 4, № 1. P. $1-14$.

3. Characterization of tobacco geminiviruses in the Old and New World/M. Paximadis, A.M. Idris, I. Torres-Jerez et al.//Arch Virol. — 1999. — V. 144, № 4. - P. $703-717$. 
4. Chatterjee A. Acquisition, transmission and host range of a begomovirus associated with yellow vein mosaic disease of mesta (Hibiscus cannabinus and Hibiscus sabdariffa)/A. Chatterjee, A. Roy, S.K. Ghosh//Australasian Plant Pathology. — 2008. — V. 37, № 5. - P. 511 - 519.

5. Council Directive 2000/29/EC of 8 May 2000 on protective measures against the introduction into the Community of organisms harmful to plants or plant products and against their spread within the Community//OJL 169, 10.7. - 2000. - P. $1-112$.

6. Diversity of DNA 1: a satellite-like molecule associated with monopartite begomovirus-DNA [beta] complexes/R.W. Briddon, S.E. Bull, I. Amin et al.//Virology. - 2004. - V. 324, № 2. - P. $462-474$.

7. Establishment of three new genera in the family Geminiviridae: Becurtovirus, Eragrovirus and Turncurtovirus/A. Varsani, J. Navas-Castillo, E. Moriones et al.//Arch Virol. — 2014. — V. 159, № 8. P. $2193-2203$.

8. Exploiting chinks in the plant's armor: evolution and emergence of geminiviruses/M.R. Rojas, C. Hagen, W.J. Lucas et al.//Annu Rev Phytopathol. — 2005. — V. 43, № 1. - P. 361 - 394.

9. Geminiviridae. In Virus Taxonomy: Ninth Report of the International Committee on Taxonomy of Viruses. London: Elsevier/M.Q. Andrew, M.J. King, E.J. Adams et al.//Academic Press. — 2012. — P. 351 374.

10. Geminivirus coat protein gene replacement alters insect specificity/R.W. Briddon, M.S. Pinner, J. Stanley et al.//Virology. — 1990. - V. 177, № 1. — P. 85 - 94.

11. Geminivirus disease complexes: An emerging threat/S. Mansoor, R.W. Briddon et al.//Trends Plant Sci. - 2003. - V. 8, № 3. - P. $128-134$.

12. Geminivirus DNA replication and cell cycle interactions/C. Gutierrez, E. Ramirez-Parra, M. Mar Castellano et al.//Vet. Microbiol. - 2004. - V. 98, № 2. - P. 111- 119.

13. Geminiviruses - models for plant DNA replication, transcription and cell cycle regulation/L. HanleyBowdoin, S.B. Settlage, B.M. Orozcoet al.//Curr. Biol. — 1999. — V. 18, № 1. - P. 71 - 106.

14. Geminiviruses: masters at redirecting and reprogramming plant processes/L. Hanley-Bowdoin, E.R. Bejarano, D. Robertson et al.//Nature Reviews Microbiology. - 2013. - V. 11, № 1. - P. 777 - 788.

15. Harlan J. Agricultural origins: Centers and Noncenters/J. Harlan//Science. - 1971. — V. 174. — P. $468-474$.

16. Incidence of begomoviruses and climatic characterisation of Bemisia tabaci-geminivirus complex in soybean and bean in Argentina/V. Alemandri, P. Rodriguez, J. Izaurralde et al.//Agriscientia. - 2012. V. 29, № 1. - P. 31 - 39.

17. Matthews R.E.F. Classification and nomenclature of viruses. Third report of the International Committee on Taxonomy of Viruses/R.E.F. Matthews//Intervirology. - 1979. — V. 12. - P. $129-296$.

18. Molecular and recombinational characterization of begomovirus infecting an ornamental plant Alternanthera sessilis: A new host of tomato leaf curl kerala virus reported in India/A. Marwal, A.K. Sahu, R. Prajapat et al.//Sci. Int. - 2013. - V. 1. - P. $51-56$.

19. Morales F.J. The ecology and epidemiology of whitefly-transmitted viruses in Latin America/ F.J. Morales, P.G. Jones//Virus Res. — 2004. - V. 100, № 1. - P. 57 - 65.

20. Moriones E. Emergence of begomovirus diseases / E. Moriones, J. Navas-Castillo, J.A. Diaz-Pendon // Recent Advances in Plant Virology. Norfolk, UK: Caister Academic Press. - 2011. - P. $301-320$.

21. Navas-Castillo J. Emerging Virus Diseases Transmitted by Whiteflies/ J. Navas-Castillo, E. FialloOlivé, S. Sánchez-Campos//Annual review of phytopathology. - 2011. - V. 49. - P. $219-248$.

22. Nawaz-ul-Rehman M.S. Evolution of geminiviruses and their satellites/M.S. Nawaz-ul-Rehman, C.M. Fauquet//FEBS Letters. - 2009. - V. 583, № 12. - P. $1825-1832$.

23. Pohl D. Synergistic pathogenicity of a phloemlimited begomovirus and tobamoviruses, despite negative interference/D. Pohl, C. Wege//J. Gen Virol. — 2007. - V. 88, № 3. - P. $1034-1040$.

24. Saleem M.H. Begomovirus transmission by mechanical inoculation, grafting, determination of host range and symptomatology/M.H. Saleem, M. Tahir, P.G. Markham//Mycopath. - 2004. - V. 2, № 2. P. $95-100$. 
25. Saunders K. Aetiology: The earliest recorded plant virus disease/K. Saunders, I.D. Bedford, T. Yahara//Nature. - 2003. - V. 422. - P. 831.

26. Seal S.E. Factors influencing begomovirus evolution and their increasing global significance: implications for sustainable control/S.E. Seal, F. Bosch, M.J. Jeger//Crit. Rev. Plant Sci. — 2006. — V. 25, № $1 .-$ P. $23-46$.

27. Tomato yellow leaf curl virus: a whitefly-transmitted geminivirus with a single genomic component/ N. Navot, E. Pichersky, M. Zeidan et al.//Virology. — 1991. — V. 185, № 1. — P. 151 - 161. 